AUTOR

Víctor Grande-López

\section{ADSCRIPCIÓN PROFESIONAL}

Doctorando en comunicación. Universidad de Cádiz

\section{TÍTULO}

El cine made in Cádiz es un gran invento

\section{CORREO-E}

victorgaez@gmail.com

\section{RESUMEN}

Las películas nos ofrecen la oportunidad de dar la vuelta al mundo descubriendo destinos extraordinarios sin movernos de nuestro asiento. En el sur de España se encuentra la provincia de Cádiz, ideal telón de fondo para el rodaje de muchas películas, se pretende en este estudio extraer las más representativas rodadas en la provincia de Cádiz entre ellas películas como Cateto a Babor (1970), que actualmente es la película con mayor audiencia en la historia de la televisión en España. Este estudio pretende ser una herramienta de trabajo para profesionales y material didáctico de conocimiento para el ámbito educativo.

\section{PALABRAS CLAVE}

Cine; turismo cinematográfico; promoción de la imagen; procesos creativos cinematográficos; educación.

\section{AUTHOR \\ Víctor Grande-López}

\section{PROFESSIONAL AFFILIATION}

Doctorando en comunicación. Universidad de Cádiz

\section{TITLE}

Movies "made in Cádiz" is a great invention

\section{E-MAIL}

victorgaez@gmail.com

\section{ABSTRACT}

Films offer us the opportunity to go around the world discovering extraordinary destinations without moving from our seats. The province of Cádiz, located in Southern Spain, a perfect landscape to film many movies. In this study we will draw the most representative movies filmed in Cádiz province, such us Cateto a Babor (1970), which nowadays is the most viewed film in the history of Spanish television. This study pretends to be a tool for professionals, material for knowledge in the academic world.

\section{KEYWORDS}

Film; Film Tourism; Image promotion; Creative processes of film; Education.

Fecha de registro: 17/05/2018

Fecha de aceptación: 15/10/2018 


\section{El cine made in Cádiz es un gran invento Víctor Grande-López}

\section{Introducción}

«El turismo es un gran invento». Ya lo decía el director de cine Pedro Lazaga en 1968, donde mostraba en esta película los beneficios que aporta el turismo a nivel económico para una ciudad, el cine nos acerca a conocer nuestra historia, viajar al pasado, a otras épocas, nos transporta a lugares, las imágenes a través del cine tienen una proyección a nivel de promoción que llega a millones de personas en todo el mundo.

Según Flores Ruiz (2015: 176) una de las tipologías de turismos que más está creciendo en los últimos años es el turismo cultural y, dentro de éste, el turismo cinematográfico (RODRÍGUEZ et al., 2013), el cual se presenta como uno de las tipologías con mayor potencial de crecimiento a la hora de diseñar la oferta turística de un destino. Para Vives García (2013: 4-8), el concepto de Turismo inducido por el cine $\left(\mathbf{M o}_{0^{-}}\right.$ vie Induced Tourism) fue acuñado por los investigadores Riley y Van Doren en 1998, al constatar la influencia del cine en la industria turística. Macionis 2004, analiza también las denominaciones: Media induced tourism, Movie induced tourism, Film induced tourism, The cinematographic tourist.

El estudio del turismo de cine es relativamente reciente en los ámbitos de investigación, se define como las visitas de los turistas a un destino como resultado de que el destino ha aparecido en la pantalla de cine (HUDSON and RITCHIE, 2006). Beeton (2005: 9) define como el lugar que sigue al éxito de una película que fue ambientada o bien rodada en una región concreta.

Según Vives García (2013: 16), el turista concibe en su mente una serie de creencias y atributos (componentes cognitivos) y una serie de motivaciones y deseos (componentes afectivos) que le llevarán a seleccionar y visitar uno u otro destino turístico (GARTNER, 1993). Beerli Palacios y Martín Santana (2002) muestran que la formación de la imagen de un destino es un concepto mental que se desarrolla a partir de múltiples fuentes de información. Para Gómez Alonso (2006) el cine ofrece al espectador lo que sucede en otros lugares. Jiménez Morales y San Eugenio (2009) indican que existe un poder visual en las imágenes de un territorio en el espectador, ejemplos se encuentran si visualizas Paris piensas en la Torre Eiffel o Egipto en las pirámides.

\section{Objetivo}

El objetivo general de este estudio es conocer los motivos por los cuales se debe elegir a la provincia de Cádiz como escenario cinematográfico ya que ayudaría a la con- 
tribución de mejoras saludables en el desarrollo económico y turístico de la provincia.

Este objetivo principal se puede desglosar en otros más específicos:

- Conocer las ventajas que tiene la provincia de Cádiz como escaparate promocional cinematográfico.

- Fomentar los recursos turísticos a través del cine que ocasionan beneficios económicos y culturales para la provincia de Cádiz.

- Analizar los conocimientos que se pueden adquirir durante el visionado audiovisual rodado en la provincia de Cádiz como recurso didáctico para el ámbito académico.

- Descubrir gracias a las producciones fílmicas lugares para visitar y localizaciones cinematográficas para futuras producciones audiovisuales en la provincia de Cádiz.

\section{El cine despierta la curiosidad del viajero}

"Viajar es vivin

Hans Christian Andersen

Pereira Domínguez (2005: 205-228) indica que el cine es el arte social de nuestro tiempo, no sólo a que en él se juntan diversas artes hasta convertirlo en un arte total, sino también al interés y aceptación que suscita en cualquier parte del planeta y entre personas de cualquier edad o condición. Los espectadores pasan de ser sujetos pasivos viendo una película a sujetos activos como espectadores-viajeros a través del escenario cinematográfico de la película visionada, quieren revivir lo que leyeron en las novelas, quieren vivir en primera persona los decorados naturales.

A. del Rey-Reguillo (2007) señala que el cine y el turismo constituyen dos industrias culturales de enorme alcance económico y mediático. Las localizaciones de las películas son elegidas por los espectadores como destinos, sus secuencias son un escaparate tanto a nivel nacional como internacional por ello es importante su estudio, saber los beneficios que nos aporta, las motivaciones y necesidades que lleva al espectador a visitar esos espacios. Este estudio pretende ser una herramienta de trabajo, material didáctico de conocimiento y una guía de localizaciones para las productoras audiovisuales, con el objetivo de conseguir una óptima promoción.
Seño Asencio (2015) señala que el cine y el turismo, supone una enorme potencialidad y oportunidad para los territorios desde una doble concepción: como emplazamiento a la industria audiovisual y como dinamizador de los recursos turísticos existentes a partir de nuevas narrativas inspiradas en la ficción. El cine deja en la memoria una serie de imágenes que hacen trabajar a la imaginación relacionándolas con nuestras experiencias o deseos.

A través de la pantalla se obtienen impulsos de emociones que influyen en nuestros actos y comportamientos de manera inconsciente. Es una poderosa máquina debido a sus posibilidades artísticas subyugantes o simplemente manipuladoras que penetran hasta el subconsciente. Un vehículo enriquecedor de cultura y comunicación que nos aproxima al conocimiento del destino pudiéndolo convertir en un potencial turístico.

\section{Metodología}

Por medio de una metodología cualitativa se trabaja la importancia que tiene un fotograma audiovisual como proceso de comunicación hacia el espectador-turista, la base de la comunicación logra un posicionamiento idóneo en la mente, capta la atención y convierte al espectador en turista potencial. Las imágenes están construidas por un proceso de técnicas cinematográficas que contienen una gran carga de componentes psicológicos y emocionales que favorecen y estimulan el interés y promueven un estímulo. Se realiza para este estudio una revisión de autores que han estudiado sobre el turismo cinematográfico y referencias bibliográficas y videográficas relacionadas con la filmografía de estudio. Se realiza una ficha cronológica de las películas más representativas que se han rodado en la provincia de Cádiz de las que se incluyen: título, año, localidad gaditana donde se ha rodado y una breve sinopsis.

Sus historias son parte de la historia de la provincia de Cádiz y de la historia de España y su visionado debido a la temática de sus producciones ayuda como recurso didáctico al ámbito educativo para diferentes estudios (Enología, Sociología, Educación infantil, Medicina, Ciencias ambientales, Turismo, Arquitectura, Música, Comunicación audiovisual, Publicidad, Gastronomía, Fotografía, Historia, etc.) y aumenta el interés del espectador por visitar esos espacios filmados. Un catálogo como herramienta de trabajo a nivel de promoción para profesionales del turismo, educadores e historiadores.

\section{El cine más representativo rodado en la provin- cia de Cádiz \\ - La España trágica (1918): rodada en Jerez de la Frontera (Cádiz). Dirigida por Rafael Salvador.}


Interpretada por Carmen Villasán y José Portes. Uno de los primeros largometrajes españoles dedicado al mundo de la tauromaquia.

- Boy (1925): rodada en Cádiz y San Fernando (Cádiz). Dirigida por Benito Perojo. Interpretado por Joaquín Carrasco. Por el amor de una condesa, Boy pide dinero a un prestamista, pero éste aparece asesinado y recaen sobre él las sospechas.

- La malcasada (1926): rodada en Jerez de la Frontera (Cádiz), Dirigida por Francisco Gómez Hidalgo. Interpretada por María Banquer y José Nieto. Es la primera película que plantea abiertamente el tema del divorcio en España. Y lo hace a través de una historia fracasada entre un torero y una actriz.

- La Lola se va a los puertos (1947): rodada en Cádiz/ Puerto de Santa María/ San Fernando/ Sanlúcar de Barrameda/Jerez de la Frontera. Dirigida por Juan de Orduña. Interpretado por Ricardo Acero y Juanita Reina. Lola parte en barco desde San Fernando a Sanlúcar al cortijo de un hombre rico, entre el hijo de éste y Lola surge un sentimiento y atracción mutua.

- Lola la piconera (1951): rodada en Cádiz. Dirigida por Luis Lucia. Interpretada por Juanita Reina y Virgilio Teixeira. En Cádiz durante la guerra de la Independencia una cantaora llamada Lola se enamora de un militar francés.

- La bella de Cádiz / La belle de Cadix (1953): rodada en Cádiz. Dirigida por Raymond Bernard. Interpretada por Carmen Sevilla y Luis Mariano. Un grupo de cineastas franceses viajan a Andalucía para rodar una película titulada La bella de Cádiz. Coproducción Francia y España.

- Carne de horca (Il terrore dell'Andalusia) (1953): rodada en Grazalema/Jerez de la Frontera. Dirigida por Ladislao Vajda. Interpretado por Rossano Brazzi y Fosco Giachetti. En el siglo XIX, en Sierra Morena y en la Serranía de Ronda proliferaban los bandoleros, quienes en solitario o reunidos sembraban el pánico asaltando a los viajeros. Coproducción España e Italia.

- $\quad$ El duende de ferez (1953): rodada en Jerez de la Frontera (Cádiz). Dirigida por Daniel Mangrané. Interpretada por Paquita Rico y Ángel Jordan. Durante las populares fiestas de la vendimia en
Jerez llega un joven profesor de Inglaterra para investigar los beneficios que tiene el vino.

- El pescador de coplas (1954): rodada en Sanlúcar de Barrameda (Cádiz). Dirigida por Antonio del Amo. Interpretado por Antonio Molina y Marujita Díaz. Entre pescadores de un puerto, dos hermanos tienen aptitudes para el cante y el baile flamenco. Un empresario madrileño les escucha cantar y quiere contratarlos. Ellos debido a que la pesca está mal terminan aceptando, uno de ellos Antonio llega a ser contratado para actuar en América.

- Suspiros de Triana (1955): rodada en Cádiz. Dirigida por Ramón Torrado, Interpretada por Paquita Rico y Antonio Riquelme. Una vendedora de flores se enamora de un cantante y le propone viajar con él, le promete un buen contrato para hacerla triunfar como artista.

- Amanecer en Puerta Oscura (1957): rodada en Zahara de la Sierra en el Parque Natural Sierra de Grazalema (Cádiz). Dirigida por José María Forqué. Interpretado por Francisco Rabal. La inquietud política condiciona el malestar social y alertan la lucha. Considerada como uno de los mejores western del cine español.

- Venta de Vargas (1959): rodada en San Fernando (Cádiz). Dirigida por Enrique Cahen Calaberry. Interpretada por Lola Flores y Rubén Rojo. En 1808 el pueblo andaluz quiere evitar la invasión de tropas de Napoleón, una bailaora gaditana interpretada por Lola Flores origina un peligroso triángulo amoroso.

- Duelo en la cañada (1959): rodada en Cádiz. Dirigida por Manuel Mur Oti. Interpretado por Leo Anchoriz y Manuel Arbó. Una célebre tonadillera que actúa en los tablados de Andalucía sufre acoso en su camerino por un conocido hacendado.

- El emigrante (1959): rodada en Cádiz. Dirigida por Sebastián Almeida. Interpretada por Dolores Abril y Juanito Valderrama. Don Joaquín, un viejo emigrante contempla su ciudad y el eco de sus fiestas, no quiere bajarse del barco porque teme enfrentarse a la ausencia total de sus seres queridos.

- La viudita naviera (1961): rodada en Cádiz. Dirigida por Luis Marquina. Interpretada por Paquita 
Rico y Arturo Fernández. En 1895 durante el Carnaval de Cádiz se casa Candelaria y al poco tiempo en Cuba fallece su esposo, Candelaria pasa a ser propietaria de un negocio de barcos.

- La becerrada (1963): rodada en el Puerto de Santa María (Cádiz). Dirigida por José María Forqué. Interpretado por Francisco Rabal y Amparo Soler Leal. Para resolver los apuros económicos de un asilo, se decide organizar una becerrada benéfica.

- Cateto a Babor (1970): rodada en San Fernando (Cádiz). Dirigida por Ramón Fernández. Interpretado por Alfredo Landa y Florinda Chico. Miguel Cañete solicita varias prórrogas para librarse del servicio militar hasta que recibe un ultimátum del Ministerio de Marina, por el que se le ordena presentarse en el cuartel de Instrucción de San Fernando.

- The last run (Fuga sin fin) (1972): rodada en Cádiz, película estadounidense. Dirigida por Richard Fleischer. Interpretada por George C. Scott. Un gánster americano retirado y afincado en España recibe un último encargo, trasladar a un delincuente fugado de prisión y a su novia.

- Cuba (1979): rodada en Cádiz/ Puerto de Santa María/Jerez de la Frontera, película estadounidense. Dirigida por Richard Lester. Interpretada por Sean Connery y Hector Elizondo. La Habana, Cuba, 1959 la revolución está a punto de estallar en la isla.

- Bolero (1984): rodada en el Puerto de Santa María (Cádiz), película estadounidense. Dirigida por John Derek. Interpretada por Bo Dereck, George Kennedy y Ana Obregón. Una atractiva mujer da la vuelta al mundo para encontrar el amante ideal y durante su visita a España mantiene un romance con un torero.

- $\quad$ El imperio del Sol (1987): rodada en Trebujena (Cádiz), película estadounidense. Dirigida por Steven Spielberg. Interpretada por Christian Bale y John Malkovich. En 1941 el ejército japonés ocupa Shanghai y la privilegiada vida de un niño inglés de clase alta llega a su fin, es separado de sus padres y enviado a un campo de concentración.

- La ley del deseo (1987): rodada en Cádiz/Conil/ Jerez de la Frontera. Dirigida por Pedro Almodóvar. Interpretada por Antonio Banderas y Euse- bio Poncela. Es la historia de un director de cine homosexual que conoce a una persona la noche del estreno de una de sus obras. Historia de un triángulo homosexual.

- $\quad$ Aris (1988): rodada en Cádiz, Vejer de la Frontera (Cádiz). Producción norteamericana de la cadena $\mathrm{ABC}$. Dirigida por Waris Hussein. Interpretada por Anthony Quinn. La vida del Aristóteles Onassis.

- Bajarse al Moro (1988): rodada en Cádiz, Algeciras (Cádiz). Dirigida por Fernando Colomo. Interpretado por Antonio Banderas y Verónica Forqué. Expresión popular usada en España para referirse al acto de ir hasta Marruecos a comprar hachís.

- Navy seals (1991): rodada en San Fernando/Cádiz/Tarifa. Película estadounidense. Dirigida por Lewis Teague. Interpretado por Charlie Sheen. Un comando de élite de la Marina, creado en 1962 por el presidente Kennedy, tienen como misión destruir los misiles de un núcleo terrorista.

- Montoyas y Tarantos (1989): rodada en Jerez de la Frontera (Cádiz). Dirigida por Vicente Escrivá. Interpretada por Cristina Hoyos y Sancho Gracia. Dos familias de etnia gitana enemistadas desde el pasado, reviven viejos rencores cuando sus hijos Ana Montoya y Manuel Taranto, se enamoran.

- Blood and sand (Sangre y arena) (1989): rodada en Jerez de la Frontera (Cádiz). Dirigida por Javier Elorrieta. Interpretada por Sharon Stone, un torero se casa con su novia de toda la vida pero se encuentra con una joven rubia, rica y ganadera, comienza a sentir algo especial marcando su vida y su carrera como torero. Coproducción España y Estados Unidos.

- $\quad$ ro soy esa (1990): rodada en Medina Sidonia (Cádiz). Dirigida por Luis Sanz. Interpretada por Isabel Pantoja y José Coronado. Una pareja va a un estreno de una película que rodaron años atrás, en ella rememoran el pasado de su propia historia.

- El día que nací yo (1991): rodada en Cádiz/ Sanlúcar de Barrameda. Dirigida por Pedro Olea. Interpretada por Isabel Pantoja y Arturo Fernández. Una gitana vende pescado en un mercado y canta los fines de semana en un tablao, un día 


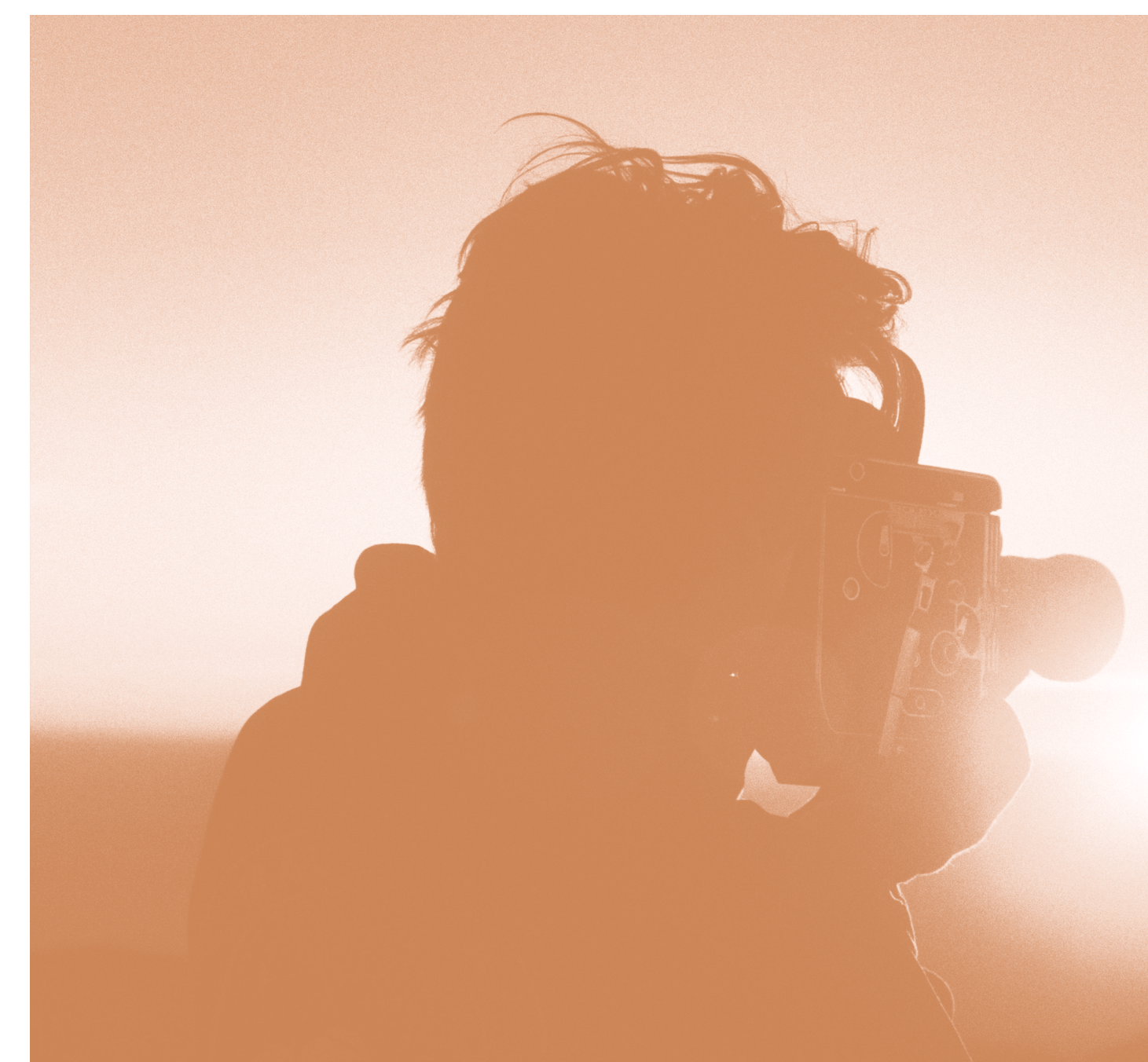


un profesor desterrado por sus ideas políticas le ofrece trabajo a la cantaora.

- El palomo cojo (1995): rodada en Sanlúcar de Barrameda (Cádiz). Dirigida por Jaime de Armiñán. Interpretado por Francisco Rabal, María Barranco y el debut en el cine de Miguel Ángel Muñoz. Los padres de un niño de diez años que padece una larga enfermedad deciden enviarlo a pasar el verano a la casa señorial de sus abuelos en Cádiz.

- Volaverunt (1999): rodada en Jerez de la Frontera (Cádiz). Dirigida por Bigas Luna. Interpretada por Aitana Sánchez Gijón, Penélope Cruz y Jordi Mollá. La Duquesa de Alba, ofrece una gala para inaugurar su nuevo palacio. Coproducción España y Francia.

- Besos para todos (2000): rodada en Cádiz. Dirigida por Jaime Chávarri. Interpretada por Emma Suárez y Eloy Azorín. Tres estudiantes son enviados por sus familias a Cádiz para ver si consiguen aprobar y llegar a ser lo que se esperan de ellos. Juntos aprenden a decidir su futuro.

- Die another day (007: muere otro día) (2002): rodada en Cádiz, película estadounidense. Dirigida por Lee Tamahori. Interpretada por Pierce Brosnan y Halle Berry. Nueva entrega de James Bond que se desarrolla en Cádiz que se convierte en la Habana y la playa de la Caleta en uno de los escenarios más emblemáticos del rodaje.

- Atún y chocolate (2004): rodada en Barbate y Zahara de los Atunes (Cádiz). Dirigida por Pablo Carbonell. Interpretada por Pablo Carbonell y María Barranco. Tres pescadores intentan sobrevivir como pueden a pesar de la crisis pesquera que vive la costa gaditana.

- Camarón (2005): rodada en San Fernando (Cádiz). Dirigida por Jaime Chávarri. Interpretada por Óscar Jaenada y Verónica Sánchez. Biografía del genio del flamenco José Monge Cruz, conocido como Camarón de la Isla.

- Los aires dificiles (2006): rodada en Barbate (Cádiz) y Zahara de los Atunes (Cádiz). Dirigida por Gerardo Herrero. Interpretada por José Luis García Pérez y Cuca Escribano. Juan Olmedo es un superviviente de un naufragio del que sólo ha podido rescatar a su sobrina y a su hermano, una persona con deficiencia mental, para olvidar su pasado se traslada a vivir a la costa gaditana.
Géneros cinematográficos

que destacan en el estudio

\section{son drama, comedia}

romántica, acción,

aventuras y el subgénero

cinematográfico musical

folclore andaluz de los

años 50, muy demandado,

exportable y rentable.

- $\quad$ Alatriste (El capitán Alatriste) (2006): rodada en Cádiz/Conil/Tarifa. Dirigida por Agustín Díaz Yanes. Interpretado por Viggo Mortensen y Elena Anaya. Alatriste, soldado al servicio de su majestad que combate en la guerra de Flandes.

- Manolete (2006): rodada en Cádiz/ El Puerto de Santa María/ Jerez de la Frontera/Sanlúcar de Barrameda. Dirigida por Menno Meyjes. Interpretada por Adrian Brody y Penélope Cruz. Basada en la biografía del torero cordobés Manolete. Coproducción España, Reino Unido, Estados Unidos, Francia, Alemania.

- Lola, la película (2007): rodada en Jerez de la Frontera/Cádiz/Sanlúcar de Barrameda. Dirigida por Miguel Hermoso. Interpretada por Gala Évora, realiza un recorrido por la vida de la folclórica Lola Flores, La Faraona.

- Che: Guerrilla (2008): rodada en el Parque Natural Los Alcornocales en Alcalá de los Gazules (Cádiz), película estadounidense. Dirigida por Steven Soderbergh. Interpretado por Benicio del Toro y Franka Potente, biopic del famoso guerrillero y revolucionario Ernesto Che Guevara.

- Febrero. Cuando la vida es carnaval (2009): rodada en Cádiz, dirigida por Nacho Sacaluga. El carnaval 
de Cádiz a través de ensayos, actuaciones callejeras, cómo cambia la vida de la ciudad de Cádiz cuando llega el mes de febrero. El carnaval como fiesta y vehículo de comunicación.

- Knight E day (Noche y día) (2010): rodada en Cádiz. Dirigida por James Mangold. Interpretado por Tom Gruise y Cameron Díaz. Un encierro de toros recorrió las calles del casco antiguo de Cádiz, como anécdota por accidente los toros se escaparon por las calles provocando un escándalo durante el rodaje.

- Miel de naranjas (2012): rodada en Jerez de la Frontera (Cádiz). Dirigida por Imanol Uribe. Interpretado por Iban Garate y Blanca Suárez. Enrique en el servicio militar presencia injusticias que le llevan a verse involucrado en arriesgadas acciones que pondrán en peligro su vida.

- Alegrías de Cádiz (2013): rodada en Cádiz. Dirigida por Gonzalo García Pelayo. Interpretado por Jeri Iglesias y Beatriz Torres. Dos amigos en los carnavales de Cádiz enamorados de la misma mujer, Pepa se llama como la primera Constitución española.

- L'aviseur (El infiltrado) (2014): rodada en Cádiz. Dirigida por Julien Leclercq. Protagonizada por Vicent Lindon. Trata sobre un ciudadano francés afincado en el sur de España, que colaboró con el organismo de aduanas de Francia como informador sobre operaciones de tráfico de drogas en el Estrecho. Película francesa

- El niño (2014): rodada en Sotogrande/Tarifa/ Algeciras, Dirigida por Daniel Monzón. Interpretada por Jesús Castro, Luis Tosar y Barbara Lennie. Sobre el narcotráfico en el estrecho de Gibraltar.

- The Beautiful Cádiz (2015): rodada en Cádiz/ Sanlúcar de Barrameda (Cádiz). dirigida por Rafael Sadoc. Interpretada por Ana Marina Eligio, Javier Aguilera, Víctor Gáez, Ana López Segovia. El sarcasmo y la ironía de un gaditano frente a la elegancia y el saber estar de una americana en la ciudad de Cádiz como telón de fondo.

- Techo y comida (2015): rodada en Jerez de la Frontera (Cádiz). Dirigida por Juan Miguel del Castillo. Interpretada por Natalia de Molina, Mariana Cordero, Mercedes Hoyos. Rocío es una madre soltera y sin trabajo, no recibe ningún tipo de ayuda ni subsidio y vive con su hijo de ocho años.

- La fiesta de los locos (2016): rodada en Cádiz. Dirigida por Manuel Iborra. El carnaval callejero invade la ciudad de Cádiz, el sarcasmo, la ironía, la diversión y humor como vehículo de expresión.

- Señor dame paciencia (2017): rodada en Sanlúcar de Barrameda (Cádiz). Dirigida por Álvaro Díaz Lorenzo. Interpretada por Rossy de Palma, Jordi Sánchez, Megan Montaner. Unos hermanos sacudidos por la muerte de su madre, se reúnen para desplazarse de Madrid a Sanlúcar de Barrameda y esparcir sus cenizas al río Guadalquivir.

- $\quad$ El extraño caso del Dr. Toñito (2017): rodada en Cádiz. Dirigida por José Manuel Serrano Cueto. Voces interpretadas por Pedro Casablanc, Alex O’Dogherty, Ana López Segovia, Manuel Tallafé. A través de unas divertidas marionetas que cobran vida, surge la historia de Toñito que desea convertirse en un ídolo del carnaval de Cádiz, para ello decide inventar una pócima.

Géneros cinematográficos que destacan en el estudio son drama, comedia romántica, acción, aventuras y el subgénero cinematográfico musical folclore andaluz de los años 50 muy demandado, exportable y rentable. Las películas que se muestran desde el inicio tratan temas como el divorcio, los prestamistas, la emigración el tener que dejar el lugar de origen principalmente por causas económicas debido al desempleo. Películas sobre bandoleros un género nacional equivalente al western norteamericano. La temática de la tauromaquia laureada fuera de nuestras fronteras en países como México, Argentina, Francia, Alemania o Bélgica y las fiestas populares destacando el carnaval de Cádiz.

En los años 70, la película Cateto a Babor rodada en San Fernando, es actualmente la película más vista en la historia de la televisión española, se emitió el 14 de enero de 1992 ante 10.078 .000 espectadores (60,5\% de share), le sigue en el ranking Ocho apellidos vascos que aun siendo emitida simultáneamente en dos canales, Telecinco y Cuatro no llegó a superarla y se quedó con 8.270.000 espectadores. En la última década, el cine español rodado en la provincia de Cádiz sus historias han estado vinculadas con temas sociales y con el carnaval de Cádiz. Películas como Alegrías de Cádiz, Febrero, cuando la vida es carnaval, The Beautiful Cádiz, La fiesta de los locos o El extraño caso del Dr. Toñito, son algunos de los ejemplos.

Sacaluga Rodríguez y Pérez García (2016) indican que el cine como arte, como transmisor de expresiones cultu- 


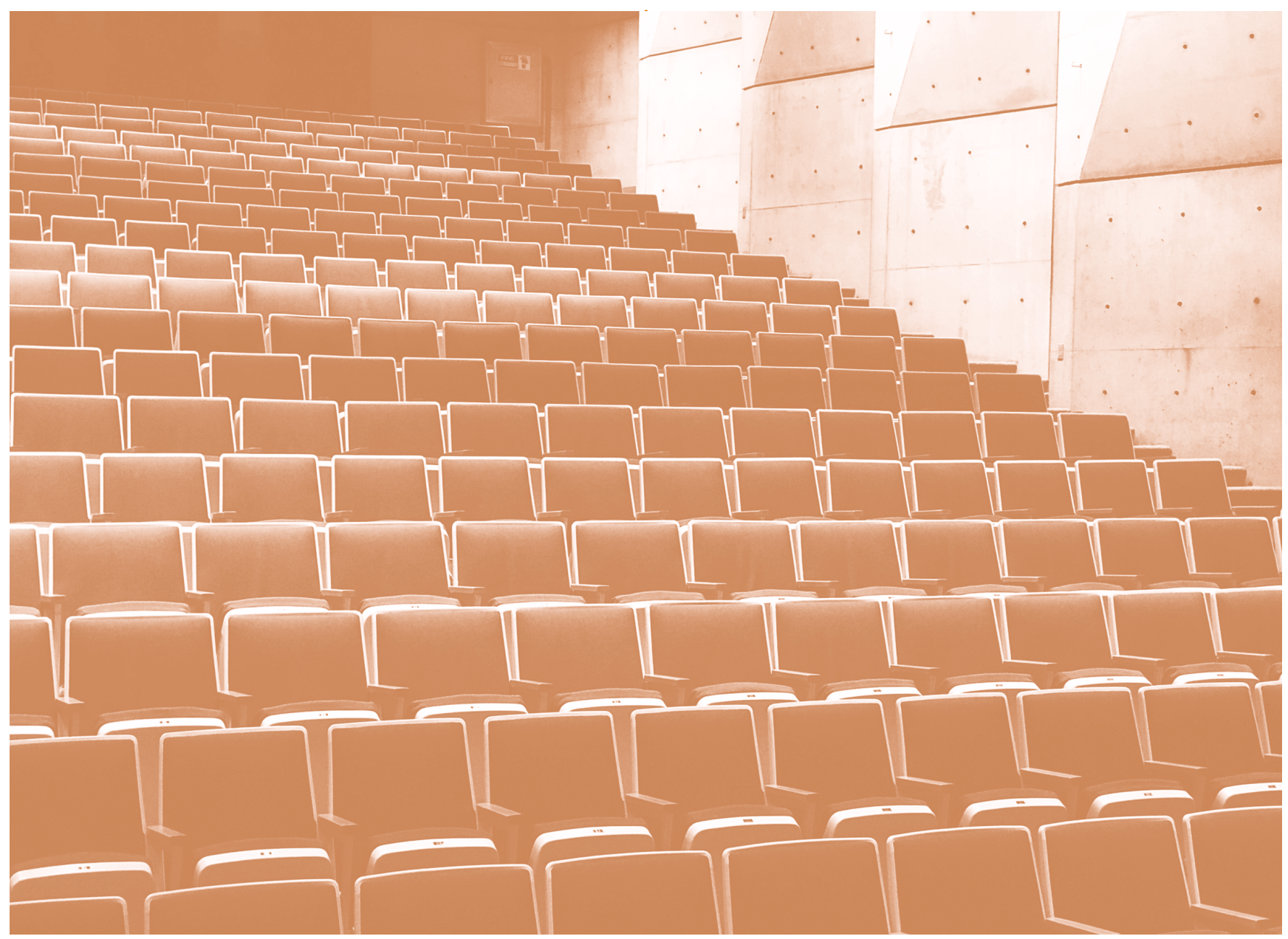

rales, como industria o como medio de comunicación se ha convertido en una de las grandes inspiraciones para el carnaval gaditano. Ya en 1966 la comparsa Los Beatles de Cádiz, nombre con el que se popularizaron Los Escarabajos Trillizos dieron el salto al cine compartiendo reparto en la película Acompáñame (1966) junto a la actriz y cantante Rocío Durcal.

Algunos de los recursos que se destacan en las películas rodadas en la provincia de Cádiz y otros que se pueden utilizar en futuras producciones son: la similitud de la ciudad de Cádiz con la Habana (Cuba), su puerto naviero con una privilegiada posición en comunicación permanente con Tánger y las Islas Canarias. La provincia cuenta con palacios, cortijos, castillos, monasterios, casas de tipo señorial, caballos de fama mundial, teatros, bodegas, áreas de vi- ñedos, plazas de toros de las más antiguas de Andalucía, el circuito de Jerez para rodajes de carreras de coches o motos, yacimientos arqueológicos importantes como las ruinas de Baelo Claudia, zonas militares. Un contraste entre sierra y mar con grandes Parques nacionales y naturales, zonas de reservas con amplia variedad paisajística, calas situadas bajo acantilados, puertos deportivos, la playa de El palmar entre los 10 mejores destinos de España para practicar surf, Tarifa capital europea del windsurf, etc. Una situación privilegiada situada entre dos continentes África y Europa.

\section{Resultados}

Se ha realizado un estudio cualitativo a través de una encuesta con estudiantes universitarios de la Univer- 
sidad de Cádiz, mujeres y hombres, aficionados al cine, de diferentes carreras universitarias y con una edad media comprendida entre los 18 años y 25 años. Sobre sus preferencias de películas extranjeras o nacionales, el 65\% de los entrevistados reconocen mostrar un mayor interés en ver películas extranjeras que películas españolas ante un 35\%. De ese $35 \%$, un 25\% de mujeres universitarias suelen estar interesadas en películas españolas ante un 10\% de hombres que suelen estar interesados en el cine español. En general todos reconocen que si ven cine español y les gusta, pero destacan que su decisión de ver películas españolas va influenciada por recomendación de personas cercanas como compañeros de clase, familiares, etc.

De las películas extranjeras que recuerdan que se rodaran en la provincia de Cádiz por este orden han sido: Die another day (007: muere otro día (2002), Knight E day (Noche y día) (2010) y El imperio del Sol (1987). De las películas nacionales que recuerdan que se han rodado en la provincia de Cádiz han destacado por este orden: El niño (2014), Señor dame paciencia (2017) y Techo y comida (2015).

Se recogen algunas impresiones sobre lo que perciben al visionar una película, se extrae del estudio que:

- La información les llega más a modo recordatorio a través de las imágenes que de las palabras. (Halle Berry en la playa de la Caleta o persecución de Tom Cruise en la película Noche y día).

- Los fotogramas de una localización en una película potencian sus gustos por una mayor estética en la observación. (Destacan Sanlúcar en la película Señor dame paciencia o las playa de Bolonia en Camarón, o la zona de Algeciras en películas como El niño).

- $\quad$ El visionado de una película les ayuda a mejorar la concienciación y conocimiento sobre el valor que aportan los recursos de esas localizaciones.

- Las películas establecen un deseo en el espectador de conocer esos lugares donde a través de la pantalla se están desarrollando experiencias inolvidables. (Destacan el interés que están teniendo de visitar Cádiz personas de otros puntos de España por la repercusión de series de tv o películas que están rodando mucho por la zona de la costa gaditana, El Palmar, Caños de Meca, Tarifa, Bolonia o por el carnaval de Cádiz).

- Les empuja y acerca a relaciones humanas que pueden comparar con sus propias vidas. (Sobre todo en películas de contenido social que muestran conciencia y reflexión como Techo y comida).

- Deseo interior de salir de la rutina e interés por querer descubrir destinos nuevos.

- Liberación al destino como escape de la rutina y de las obligaciones impuestas en el día a día.

- Estimulación de empuje motivacional Push factor y de arrastre Pull factor.

- Mayor información sobre el entorno favorece un compromiso, concienciación e inquietud para mejoras en el bienestar de la provincia.

- Nostalgia por revivir momentos pasados o costumbres que aparecen en la película.

\section{Discusión}

Se han aportado numerosos estudios sobre la incidencia que tienen las películas en la toma de decisión pero esto no quiere decir que las imágenes cinematográficas animen automáticamente a viajar a las localizaciones de los rodajes. Los medios de comunicación necesitan encontrar nuevas alternativas en un mercado cada vez más exigente, aunque la pantalla es un folleto audiovisual hacia el espectador-turista, es eficaz pero necesita una mayor promoción. Cada vez es más el interés que tienen por lograr las ciudades una mayor notoriedad de imagen a través de sus destinos, las pioneras localizaciones que crearon marca cinematográfica fueron: Nueva York, California, Reino Unido, Nueva Zelanda o París y en los destinos españoles destacan: Almería, Madrid, Málaga, Comunidad Valenciana, Barcelona, Sevilla, Canarias.

Según Palacio y Santana (2002: 5-32) el proceso de formación de la imagen de un destino se inicia a partir de la acumulación de imágenes mentales sobre el destino, información obtenida a través de diferentes fuentes y culmina con la imagen de la experiencia. Tal como explica Rodríguez Campo (2013: 259-279) es importante para un destino las acciones promocionales por medio de los estrenos cinematográficos. Un ejemplo ha sido la película Señor dame paciencia (2017) rodada prácticamente casi toda en Sanlúcar de Barrameda (Cádiz) y de la que su director Álvaro Díaz Lorenzo eligió el cine de Sanlúcar para estrenarla en primicia, antes de presentarse en las salas comerciales de toda España.

En relación al ámbito educativo durante la encuesta una estudiante de Enología no conocía la película El duende de ferez (1953) película que muestra el proceso del vino y los beneficios que tiene, la visionó en clase con sus compañeros y la han trabajado en el aula obteniendo un favorable aprendizaje significativo. Eso afirma que las películas del estudio se 
pueden trabajar como recursos didácticos en el aula y se pueden aprovechar sus contenidos fílmicos para las enseñanzas.

Grande-López y Pérez García (2016) señalan que el visionado es una actividad que sirve para evadirse, por lo que muestra un especial interés y atención, lo lúdico entretiene, motiva y no se olvida, el alumnado no siente que está siendo formado. Según los datos de la encuesta los estudiantes no conocen muchas de las películas filmadas en la provincia de Cádiz. La importancia de saber gestionar bien ese contenido es clave para generar un mayor aprendizaje. Se pueden trabajar en el aula tanto fotogramas de películas donde vengan localizaciones de la provincia y realizar estudios sociales sobre lo vivido en la época y compararlo con la actual, como realizar videos de promoción turística sobre las secuencias más significativas de nuestro cine made in Cádiz.

\section{Conclusión}

Estamos en un momento donde la interacción es vital, la tecnología genera una capacidad que hace que las ideas sean inagotables, el turismo y el cine presentan cambios muy significativos, la realidad virtual sigue avanzando y tendrá implicaciones en el viaje y en el turista transportándose virtualmente para experimentar el destino hacia donde se quieren trasladar. Los robots interactivos serán una apuesta en el sector turístico ya en hoteles en Japón existen robots entregando cosas en la habitación.

El Smartphone ha sido utilizado por más de 150 influencers españoles muchos de ellos del mundo del cine que han visitado el año pasado China durante diez días en un proyecto de promoción con el país, para que en ese viaje conozcan su cultura, gastronomía y lo compartan mediante fotos y videos a través de su teléfono en la red social Instagram con sus millones de seguidores, que en total en forma conjunta acumulan 50 millones de seguidores aproximadamente, consiguiendo un amplio escaparate visual para que la audiencia visualice su divertido viaje y en publicidad encubierta dar a conocer los lugares atractivos del país convirtiendo al seguidor social en espectador-turista. La tecnología sigue abriendo multitud de mecanismos audiovisuales para promocionar los destinos turísticos y buscar llegar hacia dónde actualmente se encuentra la audiencia.

Jan De Clerk prestigioso empresario turístico de la provincia de Cádiz habla de la necesidad de un buen posicionamiento, la importancia de dar a conocer aún más la provincia de Cádiz fuera de nuestras fronteras, Cádiz es la única provincia situada entre dos mares, el Océano Atlántico y el Mar Mediterráneo. La provincia de Cádiz destaca por su clima templado con 3.200 horas de sol al año lo que supone más de 300 días de sol. La temperatura media del agua es de 17 grados. Tiene uno los mejores climas del mundo y muchas horas de luz al día importante para las producciones audiovisuales. La provincia de Cádiz es un destino con un gran potencial para que las producciones cinematográficas sigan filmando historias, favorecería la economía, la cultura y una promoción turística saludable para la provincia.

"El valor de un viaje no está en el tiempo que dura, sino en la intensidad con que lo vives, por eso existen momentos inolvidables, cosas inexplicables y personas incomparables»

Fernando Pessoa

\section{Bibliografía}

Beerli Palacios A. y Martín Santana J. (2002). «El proceso de formación de la imagen de los destinos turísticos: una revisión teórica». Estudios Turísticos, n ${ }^{\circ}$ 154, pp. 5-32.

BEETON, S. (2005). FilmInduced Tourism, Channel View Publications.

CALLARISA, L. J. (2010). La identidad del territorio factor estratégico. IV Foro Innovem Junts: El territorio, factor estratégico.

DOMÍNGUEZ AZGUE, J. (2014). Análisis de la imagen de destino a través de la cinematografia, Tesina, Universidad de Málaga.

ELIZAGARTE GUTIÉRREZ, V. (2007). «Comercio y Ciudad. La misión del marketing de ciudades en el desarrollo de la competitividad del comercio urbano». Mediterráneo económico, 11, pp. 299-312.

GARCÍA, A. y ALBURQUERQUE, F. J. (2003). «El turismo cultural y el de sol y playa: ¿sustitutivos o complementarios?». Cuadernos de turismo, n 11, pp. 97-105.

GÓMEZ ALONSO, R. (2006). «El turismo no es un gran invento: Aperturismo y recepción del ocio y consumo a través del cine español de los 60». Área Abierta, n ${ }^{\circ} 15$.

GRANDE-LÓPEZ, V. y PÉREZ GARCÍA, Á. (2016). «Personajes de animación con discapacidad a través de una perspectiva educativa». Creatividad y sociedad, $\mathrm{n}^{\circ} 25$, pp. 259-28.

FLORES RUIZ, D. (2015). «Turismo cinematográfico y desarrollo económico local. El Festival de cine de Huelva». Cuadernos de Turismo, no 36, pp. 175-196.

JIMÉNEZ MORALES, M. y SAN EUGENIO, J. (2009). «Identidad territorial y promoción turística: la organización de eventos como estrategia de creación, consolida- 
ción y difusión de la imagen de marca territorio». ZER, v. 14, $n^{\circ} 26$, pp. 277-297.

MUÑOZ BENITO, R. (2016). «El turismo como sector estratégico en las etapas de crisis y desarrollo de la economía española». International journal of scientific management and tourism, v 2, no (4), pp. 81-115.

PEREIRA DOMÍNGUEZ, M ${ }^{\mathrm{a}}$ G. (2005) «Cine y Educación Social». Revista de Educación. Monográfico Educación no Formal, no 338, pp.205-228.

PÉREZ GARCÍA, Á. (2015). «El sistema educativo español bajo la mirada creativa del Carnaval de Cádiz». Creatividady sociedad, no 24, pp. 32-63.

REY-REGUILLO, A. (2007). Cine Imaginario y Turismo. Estrategias de seducción, Madrid, Tirant lo Blanch, pp. 7-31.

RODRÍGUEZ GAMPO, M. (2013). «Nuevos segmentos turísticos culturales. Una aproximación al comportamiento del consumidor turístico cinematográfico». Cuadernos de turismo, $\mathrm{n}^{\circ} 32$, pp. 259-279.

ROSILLO RUBIO, L. (2015). «El patrimonio urbano y natural andaluz a través del cine. La evolución visual del paisaje cultural como crítica histórico-artística». E-rph-Revista electrónica de Patrimonio Histórico, nº 14, pp. 204-225.

SACALUGA RODRÍGUEZ, I. y PÉREZ GARCÍA, Á. (2016). «Carnaval de Cádiz y cine, una relación recíproca».

SEÑO ASENGIO, F. (2015). «Una aproximación al turismo inducido por el cine. El caso de Osuna y Juego de tronos». Cuadernos de los amigos de los museos de Osuna, n.17.

VIVES GARCÍA, M. (2013). Turismo inducido por el cine: aplicación del caso a la ciudad de Barcelona. Máster en dirección y planificación de turismo, especialización: destinos.

ZAMUDIO VEGA, L. (2011). «Los imaginarios en la percepción de los lugares turísticos». Imagonautas, $\mathrm{n}^{\circ} 2$ (1), pp. 114-137.

\section{Referencias web}

http://www.filmaffinity.com 